\title{
Haz muscular apicobasal del ventrículo izquierdo, ¿un marcador de miocardiopatía hipertrófica?
}

\author{
Left ventricular apical-basal muscle bundle. A marker of hypertrophic cardiomyopathy?
}

Óscar U. Preciado-Gutiérrez¹, Andrés Preciado-Anaya², Jaime Ortiz-Velázquez', Rafael Alemán-Villalobos ${ }^{3}$ y Héctor Barajas-Martíne $Z^{*}$

${ }^{1}$ Departamento de Medicina, Universidad de Guanajuato, León, Gto., México; ${ }^{2}$ Departamento de Cardiología Nuclear y Tomografía computarizada, Centro de investigación Cardimax, Hospital Siena del Moral, León, Gto., México; ${ }^{3}$ Departamento de Riesgo Cardiovascular, Secretaría de Salud, Lagos de Moreno, Jal., México; ${ }^{4}$ Department of Cardiovascular Research, Lankenau Institute for Medical Research, Pennsylvania, Wynnewood, EE.UU.

El haz muscular apicobasal (HAB) del ventrículo izquierdo $(\mathrm{VI})$ es un posible marcador morfológico de miocardiopatía hipertrófica (MCH), adicional a otras expresiones fenotípicas asociadas a la enfermedad, como criptas miocárdicas, alteraciones en la válvula mitral, la arquitectura muscular papilar o la morfología ventricular derecha ${ }^{1}$, además de la propia hipertrofia del $\mathrm{VI}^{2}$. La $H A B$ se extiende desde la región apical a la porción más basal del septum o de la pared anterior.

En un estudio, la estructura se encontró en el $63 \%$ de los portadores de $\mathrm{MCH}$ y en el $60 \%$ de sus familiares genotipo positivo/fenotipo negativo $(\mathrm{G}+/ \mathrm{F}-)$ y no se encontró diferencia respecto a la presencia de la $\mathrm{HAB}$ entre $\mathrm{MCH}$ con y sin mutación en genes de la sarcómera'.

Se trata de un paciente de sexo masculino de 48 años, $170 \mathrm{~cm}$ y $80 \mathrm{~kg}$, sedentario, nunca estudiado para $\mathrm{MCH}$, sin hipertensión arterial ni antecedente de muerte súbita en la familia u otras comorbilidades.

Fue enviado por dolor precordial opresivo de inicio reciente e intermitente, no relacionado a esfuerzos, movimientos respiratorios, postura ni a la digitopresión en parrilla costal, sin otra sintomatología. No se identificaron criterios de hipertrofia del VI en el electrocardiograma de reposo.
La angiotomografía mostró arterias coronarias normales e hipertrofia generalizada leve del $\mathrm{VI}$, con un grosor parietal máximo de $15 \mathrm{~mm}$ en diástole, con un haz muscular contráctil único (Fig. 1) que se extiende a lo largo de la pared anterior desde la región apical a la basal, no insertada en la válvula mitral, hallazgo incidental de localización y morfología similar al $\mathrm{HAB}$ de $\mathrm{MCH}$, signo que puede justificar la búsqueda de esta miocardiopatía, subdiagnosticada en la práctica cardiológica diaria.

\section{Financiamiento}

El presente trabajo no ha recibido ninguna beca específica de agencias de los sectores público, comercial, o sin ánimo de lucro.

\section{Conflicto de intereses}

Los autores declaran no tener conflicto de intereses.

\section{Responsabilidades éticas}

Protección de personas y animales. Los autores declaran que para esta investigación no se han realizado experimentos en seres humanos ni en animales.

\section{Correspondencia:}

*Héctor Barajas-Martínez

E-mail: barajash69@ hotmail.com
Disponible en internet: 21-01-2021 Arch Cardiol Mex. 2021;91(4):512-513 www.archivoscardiologia.com echa de recepción: 10-09-2020

Fecha de aceptación: 21-12-2020 DOI: 10.24875/ACM.20000423

\section{lo open access bajo la licencia} CC BY-NC-ND (http://creativecommons.org/licenses/by-nc-nd/4.0/). 


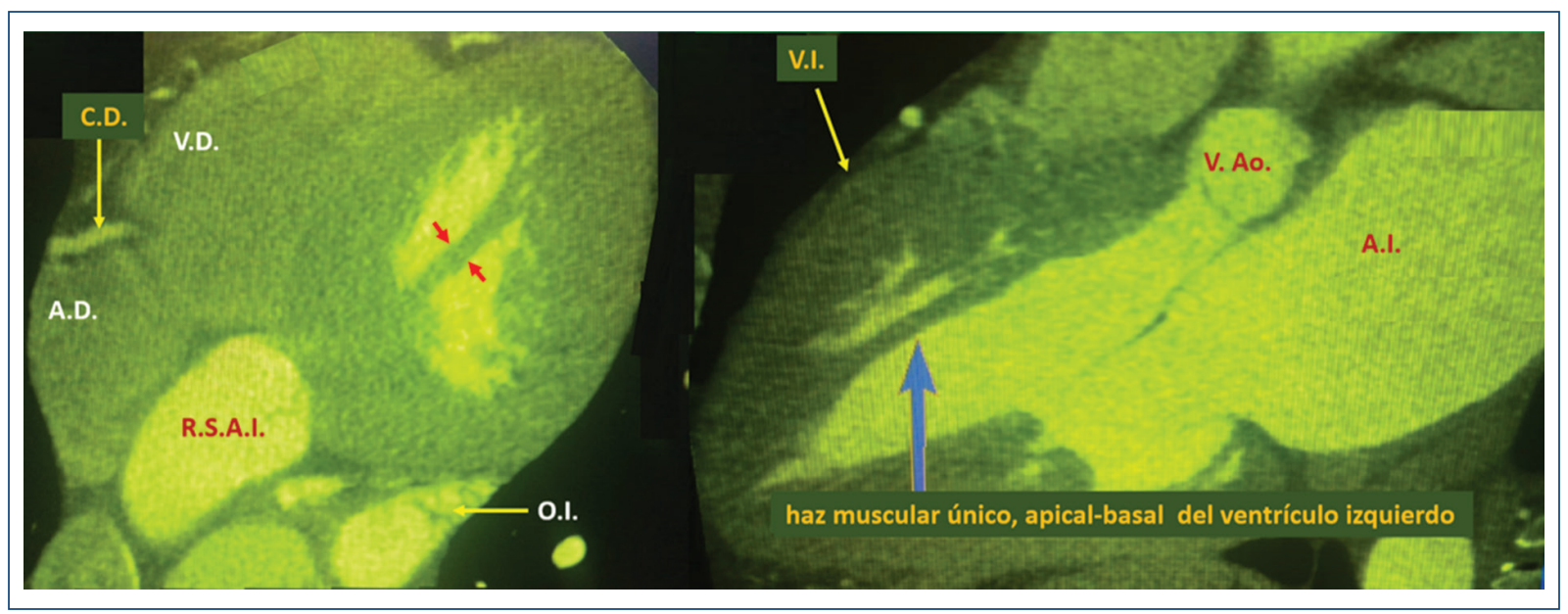

Figura 1. Angiotomografía cardiaca. En la imagen izquierda se observa señalado por las flechas rojas el haz apicobasal del ventrículo izquierdo, desde un plano axial, que se aprecia a la derecha desde una vista sagital. AD: aurícula derecha; VD: ventrículo derecho; OI: orejuela izquierda; RSAI: región superior de la aurícula izquierda; Al: aurícula izquierda; VI: pared anterior del ventrículo izquierdo; VAo: válvula aórtica.

Confidencialidad de los datos. Los autores declaran que han seguido los protocolos de su centro de trabajo sobre la publicación de datos de pacientes.

Derecho a la privacidad y consentimiento informado. Los autores declaran que en este artículo no aparecen datos de pacientes.

\section{Bibliografía}

1. Gruner C, Chan RH, Crean A, Rakowski H, Rowin EJ, Care M, et al. Significance of left ventricular apical-basal muscle bundle identified by cardiovascular magnetic resonance imaging in patients with hypertrophic cardiomyophaty. Eur Heart J. 2014;35:2706-13.

2. Olivotto I, Maron MS, Autore C, Lesser JR, Rega L, Casolo G, et al. Assessment and significance of left ventricular mass by cardiovascular magnetic resonance in hypertrophic cardiomyopathy. J Am Coll Cardiol. 2008;52:559-66 